OPEN ACCESS

Edited by:

Xiaodong Zhuang

The First Affiliated Hospital of Sun Yat-Sen University, China

Reviewed by: Yunzhao Hu,

Shunde Hospital of Southern Medical University Affiliated Chencun

Hospital, China

Xinhua Xiao,

Peking Union Medical College Hospital (CAMS), China

${ }^{*}$ Correspondence:

Хuyu $\mathrm{He}$

hexuyusci@163.com

tThese authors have contributed equally to this work and share first authorship

Specialty section

This article was submitted to Cardiovascular Metabolism, a section of the journal Frontiers in Cardiovascular Medicine

Received: 06 March 2021 Accepted: 19 April 2021 Published: 12 May 202

Citation:

Li M, Chen G, Feng Y and He X (2021) Stress Induced Hyperglycemia in the Context of Acute Coronary Syndrome:

Definitions, Interventions, and Underlying Mechanisms. Front. Cardiovasc. Med. 8:676892.

doi: 10.3389/fCVm.2021.676892

\section{Stress Induced Hyperglycemia in the Context of Acute Coronary Syndrome: Definitions, Interventions, and Underlying Mechanisms}

\author{
Mingmin $\mathrm{Li}^{+}$, Guo Chen ${ }^{\dagger}$, Yingqing Feng ${ }^{\dagger}$ and Xuyu $\mathrm{He}^{*}$ \\ Department of Cardiology, Guangdong Provincial Key Laboratory of Coronary Heart Disease Prevention, Guangdong \\ Cardiovascular Institute, Guangdong Provincial People's Hospital, Guangdong Academy of Medical Sciences, Guangzhou, \\ China
}

Elevation of glucose level in response to acute coronary syndrome (ACS) has been recognized as stress induced hyperglycemia $(\mathrm{SIH})$. Plenty of clinical studies have documented that SIH occurs very common in patients hospitalized with ACS, even in those without previously known diabetes mellitus. The association between elevated blood glucose levels with adverse outcome in the ACS setting is well-established. Yet, the precise definition of SIH in the context of ACS remains controversial, bringing confusions about clinical management strategy. Several randomized trials aimed to evaluate the effect of insulin-based therapy on outcomes of ACS patients failed to demonstrate a consistent benefit of intensive glucose control. Mechanisms underlying detrimental effects of SIH on patients with ACS are undetermined, oxidative stress might play an important role in the upstream pathways leading to subsequent harmful effects on cardiovascular system. This review aims to discuss various definitions of $\mathrm{SIH}$ and their values in predicting adverse outcome in the context of ACS, as well as the effect of intensive glucose control on clinical outcome. Finally, a glimpse of the underlying mechanisms is briefly discussed.

Keywords: stress induced hyperglycemia, acute coronary syndrome, admission blood glucose, intensive glucose control, oxidative stress

\section{INTRODUCTION}

Stress-induced hyperglycemia (SIH) is an acute response of the bodies to many critical illnesses, including acute coronary syndromes (ACS) (1). Many observational studies have documented that hyperglycemia occurs frequently among patients hospitalized with ACS, even those without diabetes mellitus (1-3). It has been well-established that elevated glucose is associated with increased in-hospital and long-term mortality in ACS patients, especially in non-diabetic patients (4-10). Yet, hyperglycemia is not identified as an independent risk factor of ACS to date. Many questions regarding the relationship between SIH and ACS remain unclarified. For example, which glucose metrics, such as the blood glucose on admission (ABG), the average blood glucose, or the glucose variability (GV), is the most appropriate measurement of hyperglycemia and best correlated to the poor outcome; what the cut-off values that precisely define SIH are; whether there's any difference between cut-off values in the presence and absence of 
recognized diabetes mellitus; whether glucose-lowering therapy can improve the prognosis of ACS patients with SIH; and finally, what the mechanisms underlying SIH in the ACS setting are. This article aims to address some of the undetermined issues based on the present available data.

\section{DEFINING SIH IN THE CONTEXT OF ACS Defining SIH With ABG}

Despite numerous studies regarding SIH have been published, there's currently no uniform definition for SIH in the setting of ACS. Most early studies defined hyperglycemia by the first available glucose value or $\operatorname{ABG}(1,4,5,8,11-13)$. The most acceptable description of ABG refers to the first acquired blood glucose within $24 \mathrm{~h}$ of admission $(1,7)$. Nevertheless, the cutpoint of ABG used to define hyperglycemia in patients with ACS was different from study to study. Back to 2008, the American Heart Association (AHA) Scientific Statement on Hyperglycemia and Acute Coronary Syndrome suggested using an ABG level $>140 \mathrm{mg} / \mathrm{dL}$ as the definition of hyperglycemia under such circumstances (6). Evidence behind this recommendation mainly came from retrospective observational studies. In a national retrospective study of 141680 elderly acute myocardial infarction (AMI) patients, non-diabetic patients with higher ABG (range from $>110$ to $140 \mathrm{mg} / \mathrm{dL}$ ) had increased risk of both 30-day and 1-year mortality compared with patients whose ABG was $\leq 110 \mathrm{mg} / \mathrm{dL}$. In contrast, increased mortality was observed only in those with an ABG $>240 \mathrm{mg} / \mathrm{dL}$ among diabetic AMI patients (4). Another study found AMI patients with a baseline glucose level $<140 \mathrm{mg} / \mathrm{dL}$ had lower 30-day mortality compared to those with higher baseline glucose (14). Similarly, Buturlin et al. reported in a recent study of 4,520 ACS patients that mildly elevated ABG with glucose levels $<140 \mathrm{mg} / \mathrm{dL}$ was not independently associated with increased 1-year mortality in non-diabetic patients (15). In a meta-analysis of 15 relatively small studies which discussed the association between ABG and ACS outcomes, Capes et al. indicated that among nondiabetic patients with AMI, the relative risk of in-hospital death in those with an ABG level $>110 \mathrm{mg} / \mathrm{dL}$ was 3.9 compared with that of patients who were normoglycemic. On the contrary, among diabetic AMI patients, a greater risk of in-hospital death was observed only in patients whose ABG level $\geq 180 \mathrm{mg} / \mathrm{dL}$ (1). The phenomenon that cut-off values of $A B G$ for predicting adverse outcome differed between diabetic and non-diabetic AMI patients was reported in similar studies $(4,8)$. An appropriate reason for such discrepancy might be the unawareness of different baseline glucose metabolic status between diabetic and non-diabetic patients. The ABG level is influenced by both acute physiological stress and chronic baseline glycemic levels, especially in patients with established diabetes mellitus. It's obviously that using a single cut-off value of ABG to define SIH, regardless of the previous glucose metabolic status, is not compelling. Therefore, new metrics including glycemic gap and stress hyperglycemia ratio (SHR), which eliminate the interference of chronic glycemic levels, were introduced (16-18).

\section{Defining SIH With Glycemic GAP/SHR}

The glycemic gap is calculated from the ABG minus the HbAlc derived average glucose level. A recent study showed that glycemic gap instead of ABG was associated with increased mortality (9). Similarly, SHR is calculated from ABG divided by the HbAlc derived average glucose level, which is also expressed as acute-to-chronic glycemic ratio in some articles. In a prospective study including 1,553 AMI patients, the prognostic power of glycemic ratio for in-hospital mortality was particularly evident in diabetic patients. However, among nondiabetic patients, both glycemic ratio and ABG had a similar prognostic accuracy (17). Another study of patients with STsegment elevation myocardial infarction (STEMI) found that the glycemic ratio was closely associated with an increased risk for poor in-hospital outcome among both diabetic and nondiabetic patients (19). In contrast, ABG showed an association with poor in-hospital outcome only in non-diabetic patients. A recent randomized study evaluated the predictive value of SHR for long-term outcome in both diabetic and nondiabetic patients with STEMI. It included 6,287 STEMI patients and followed up over 5 years, and finally demonstrated that high SHR was significantly associated with worse long-term outcome in non-diabetic, instead of diabetic patients (10). Coincidently, Yang et al. reported in an AMI cohort that patients with a high SHR were at increased risk for longterm MACCE, defined as composites of all-cause death, nonfatal myocardial infarction, and non-fatal stroke (20). Again, when the same analysis was applied to diabetic patients, the risk of MACCE did not differ between patients with and without a high SHR. Hence, the predictive value of SHR was similar among diabetic and non-diabetic patients for in-hospital outcomes, but differed for long-term outcomes. The underlying mechanisms is unknown, one possible explanation might be the effect of SIH is masked by diabetes itself, given the fact that diabetes contributes to poor long-term prognosis in AMI patients (10).

\section{Defining SIH With GV}

Both $\mathrm{ABG}$ and SHR are derived from one blood glucose test. The nature of the metrics determines that it cannot reflect the full profile of glucose swings in the ACS setting. Patients with similar mean glucose levels can have markedly different glucose excursions. Meanwhile, glucose fluctuations can exert deleterious effects on both endothelial function and oxidative stress $(21,22)$. Previous studies reported increasing GV conferred a higher risk of mortality among critically ill patients, independent from mean glucose levels (23). Gong $\mathrm{Su}$ et al. demonstrated in an AMI cohort that GV, indicated as the mean amplitude of glycemic excursions (MAGE), was associated with increased risk of MACE instead of ABG or HbA1c (24). In a further study of 256 non-diabetic STEMI patients, high GV but not ABG was turned out to be associated with 3-month MACE (25). Subsequent studies emerged with similar conclusions that GV was a predictor of prognosis in patients with ACS regardless of the diabetic status (26-28). In addition, an elevated GV was suggested to be associated with hypoglycemia, an independent risk 
factor for patients with coronary artery disease $(29,30)$. Yet, among several methods to quantify GV, such as standard deviation, MAGE and coefficient of variation, there is no universally accepted "gold standard." Given different methods being utilized in studies, the results should be interpreted with caution. Besides, there were a few studies focusing on other metrics, such as fasting glucose (FG). Considering the definition of FG used in these studies, it seems to be an alternative index for ABG. However, FG within $24 \mathrm{~h}$ of admission was reported to be associated with both increased short and long-term mortalities only in diabetic patients with ACS (31-33).

With present methodology, it seems unable to describe the complete profile of SIH in the ACS setting by utilizing a single glucose metrics. Moreover, an optimal definition of $\mathrm{SIH}$ should have a similar accuracy in predicting the cardiovascular outcomes among both diabetic and non-diabetic patients. Further investigations regarding how to precisely define or draw the outline of SIH are in demand.

\section{INTERVENTIONS}

Although it's widely accepted that ACS patients presenting with hyperglycemia are at increased risk for adverse outcome, it remains to be illustrated whether hyperglycemia is a direct mediator of poor outcome, or it's simply a marker indicating a greater disease severity. To address the issue, large randomized clinical trials of glucose control in hospitalized ACS patients are requisite. In contrast to plenty of clinical trials of target-driven glucose control in chronic hyperglycemia patients, a few trials exploring the optimal glycemic target for ACS patients have been performed (Table 1).

To our knowledge, DIGAMI was the first randomized clinical trial designed to evaluate the effect of intensive glucose control in AMI patients presenting with SIH. A total of 620 patients presenting with AMI, either had recognized diabetes mellitus or had a blood glucose level $>11 \mathrm{mmol} / \mathrm{L}$ without diabetes, were enrolled (34). Patients were randomized into intervention arm with insulin-glucose infusion followed by multidose subcutaneous insulin and control arm with conventional therapy. The primary endpoint was all-cause mortality at 3 months. Patients from the insulin arm had significantly lower glucose levels compared to the control arm during the interventional period. Although there was no difference between two treatment groups for the primary outcome, reduced all-cause mortality was observed in the insulin arm at both 1- and 3.4-year follow up points (35). Nevertheless, given that over $80 \%$ of the patients had recognized diabetes mellitus and the insulin treatment lasted 3 months, it's hard to tell whether acute or chronic intensive glucose control contributed more to the reduced mortality. Although similar studies emerged subsequently, DIGAMI was the only trial demonstrating a survival benefit from intensive glucose control. The following study DIGAMI 2 was performed to compare the effects of 3 different treatment strategies in diabetic patients with AMI. Unexpectedly, no difference in the glucose control was achieved between the treatment groups, and it failed to demonstrate early and continued insulin-based intense glucose control could reduce mortality (36).

In the HI-5 study, $40 \%$ of the enrolled AMI patients were hyperglycemic without known diabetes. Patients were randomized to receive either insulin-based therapy or conventional therapy (37). There was no difference between two treatment arms in the mean 24-h blood glucose level. Despite a lower incidence of cardiac failure and reinfarction in the intervention arm within 3 months, HI-5 failed to demonstrate a reduced mortality at the in-hospital stage, 3 or 6 months. Nerenberg et al. enrolled 287 patients with AMI and hyperglycemia and randomly assigned them to either tight glucose control or usual care (38). At $24 \mathrm{~h}$, patients from the tight glucose control arm had significant lower glucose levels compared to those from control arm, yet the 90-day mortality didn't differ between two arms. Besides, in a study by Marfella et al., 50 hyperglycemic patients diagnosed with AMI were randomized to intensive glycemic control (target glucose level 80-140 mg/dL) or conventional glycemic control for almost 3 days before surgery (39). Compared to the control group, patients in the intensive group had higher ejection fraction, less oxidative stress, less inflammation in peri-infarcted specimens. In their following studies, tight glucose control in hyperglycemic patients with STEMI brought benefits to both myocardial salvage and in-stent restenosis at 6 months after onset $(40,41)$.

Given the inconsistent results of clinical trials about glucose control in AMI patients, de Mulder et al. realized the inappropriate glucose target might be the problem. In their randomized trial BIOMArCS-2, a total of 294 patients with ACS and hyperglycemia were randomized to either intensive glucose control or conventional management (42). The target glucose levels were $85-110 \mathrm{mg} / \mathrm{dL}$ and $<288 \mathrm{mg} / \mathrm{dL}$, respectively. The primary endpoint was high-sensitive troponin $T$-value $72 \mathrm{~h}$ after admission. Glucose levels in the intensive arm were significantly lower than that of control arm within $36 \mathrm{~h}$, but equalized by $72 \mathrm{~h}$. Unexpectedly, there're no difference between the groups in the troponin $T$-values at $72 \mathrm{~h}$. In contrast, a median follow-up of 5.1 years of the study reported higher rates of mortality at both 30 days and long term, suggesting intensive glucose control in the early phase of AMI resulted in persistent harmful effects (43). Compared to DIGAMI, BIOMArCS-2 had a more stringent target glucose level in the intervention arm. Although further analysis of BIOMArCS-2 didn't demonstrate an association between hypoglycemia and increased mortality, a lower glucose target might be responsible for the opposite results gained from DIGAMI and BIOMArCS-2.

Additionally, insights from the cardiovascular outcome trials of new glucose-lowering drugs, including Glucagon-Like Peptide 1 Receptor Agonists (GLP-1 RAs) and Sodium-Glucose CoTransporter 2 (SGLT-2) inhibitors (44-46), indicated a new management strategy on hyperglycemia which focused on clinical outcomes directly instead of just glucose control itself. Despite protective effects of GLP-1 RAs and SGLT-2 inhibitors on ischemia heart proved in animal infarction models (47-51), few trials have been performed in humans in the ACS setting. A pilot study found that STEMI patients treated with exenatide at the time of PCI had improved salvage of myocardium (52). 
TABLE 1 | Randomized trials designed to compare effect of intensive glycemic control with that of standard therapy in patients presenting with ACS and associated SIH.

\begin{tabular}{|c|c|c|c|c|c|c|c|}
\hline $\begin{array}{l}\text { Clinical trial } \\
\text { (year) }\end{array}$ & $\begin{array}{l}\text { Study } \\
\text { population }\end{array}$ & $\begin{array}{c}\text { Number of } \\
\text { patients } \\
\text { (percentage of } \\
\text { patients without } \\
\text { known diabetes) }\end{array}$ & $\begin{array}{c}\text { Admission } \\
\text { glycemia (mg/dL) }\end{array}$ & $\begin{array}{l}\text { Intervention } \\
\text { glycemic target } \\
\text { (mg/dL) }\end{array}$ & $\begin{array}{l}\text { Achieved glycemic } \\
\text { target (intervention } \\
\text { vs. control) } \\
\text { (mg/dL) }\end{array}$ & Primary endpoint & Result \\
\hline $\begin{array}{l}\text { DIGAMI } \\
\text { (1995) }\end{array}$ & AMl & $\begin{array}{c}620 \\
(13 \%)\end{array}$ & $>198 \mathrm{mg} / \mathrm{dL}$ & $\begin{array}{l}126-180 \mathrm{mg} / \mathrm{dL} \text { in } \\
\text { acute phase }\end{array}$ & $\begin{array}{l}148 \\
\text { vs. } \\
162 \mathrm{mg} / \mathrm{dL} \text { at } \\
\text { discharge }^{\star}\end{array}$ & $\begin{array}{l}\text { Mortality at } 3 \\
\text { months }\end{array}$ & NS \\
\hline $\begin{array}{l}\text { DIGAMI } 2 \\
\text { (2005) }\end{array}$ & ACS & $\begin{array}{l}1,253 \\
(\mathrm{NA})\end{array}$ & $>198 \mathrm{mg} / \mathrm{dL}$ & $\begin{array}{l}\text { Group 1: 90-126 } \\
\text { mg/dL(fasting), }<180 \\
\text { mg/dL (non-fasting) } \\
\text { Group 2: 126-180 } \\
\text { mg/dL }\end{array}$ & $\begin{array}{l}163.8 \\
\text { vs. } \\
163.8 \mathrm{mg} / \mathrm{dL} \text { during first } \\
24 \mathrm{~h} \text { (NS) } \\
\text { A1c } ~ \\
\text { vs. } \\
6.8 \% \text { by the end of } \\
2 \text {-year follow-up (NS) }\end{array}$ & $\begin{array}{l}\text { All-cause mortality } \\
\text { difference between } \\
\text { group } 1 \text { and } 2\end{array}$ & NS \\
\hline $\begin{array}{l}\text { Marfella } \\
\text { (2009) }\end{array}$ & $\begin{array}{l}\text { AMI } \\
\text { (CABG) }\end{array}$ & $\begin{array}{c}50 \\
(58 \%)\end{array}$ & $\geq 140 \mathrm{mg} / \mathrm{dL}$ & $\begin{array}{l}\text { 80-140 mg/dL for } \\
\text { intervention arm } \\
\text { 180-200 mg/dL for } \\
\text { control arm }\end{array}$ & $\begin{array}{l}162.7 \\
\text { vs. } \\
192.4 \mathrm{mg} / \mathrm{dL}^{*}\end{array}$ & $\begin{array}{l}\text { LVEF, oxidative } \\
\text { stress, apoptosis }\end{array}$ & $\begin{array}{l}\uparrow \text { LVEF}^{\star} \\
\downarrow \text { oxidative stress } \\
\text { and apoptosis }\end{array}$ \\
\hline $\begin{array}{l}\text { Marfella } \\
\text { (2013) }\end{array}$ & $\begin{array}{l}\text { STEMI } \\
\text { (pPCl) }\end{array}$ & $\begin{array}{c}106 \\
(62 \%)\end{array}$ & $\geq 140 \mathrm{mg} / \mathrm{dL}$ & $\begin{array}{l}80-140 \mathrm{mg} / \mathrm{dL} \text { for } \\
\text { intervention arm } \\
180-200 \mathrm{mg} / \mathrm{dL} \text { for } \\
\text { control arm }\end{array}$ & $\begin{array}{l}144 \\
\text { vs. } \\
201 \mathrm{mg} / \mathrm{dL}^{* *}\end{array}$ & Myocardial salvage & $\begin{array}{l}\uparrow \text { Myocardial } \\
\text { salvage }\end{array}$ \\
\hline $\begin{array}{l}\text { RECREATE } \\
\text { (2012) }\end{array}$ & STEMI & $\begin{array}{c}287 \\
(72 \%)\end{array}$ & $\geq 144 \mathrm{mg} / \mathrm{dL}$ & 90-117 mg/dL & $\begin{array}{l}117.5 \\
\text { vs. } \\
142.9 \mathrm{mg} / \mathrm{dL}^{* *}\end{array}$ & $\begin{array}{l}\text { Difference in mean } \\
\text { glucose levels at } \\
24 \mathrm{~h}\end{array}$ & $\downarrow$ Glycemia \\
\hline $\begin{array}{l}\text { BIOMArKS2 } \\
(2013)\end{array}$ & $\begin{array}{l}\text { ACS } \\
(\mathrm{pPCl})\end{array}$ & $\begin{array}{l}280 \\
(90 \%)\end{array}$ & 140-288 mg/dL & $85-110 \mathrm{mg} / \mathrm{dL}$ & $\begin{array}{l}112 \\
\text { vs. } \\
\approx 130 \mathrm{mg} / \mathrm{dL}^{\star \star}\end{array}$ & $\begin{array}{l}\text { hsTropT } 72 \mathrm{~h} \text { after } \\
\text { admission }\end{array}$ & NS \\
\hline
\end{tabular}

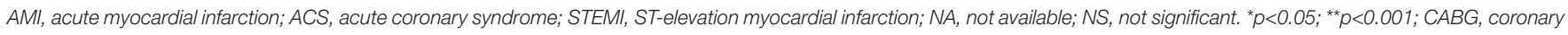
artery bypass sugery; $\mathrm{PPCl}$, primary percutaneous coronary intervention; LVEF, left ventricular ejection fraction; ISR, in-stent restenosis; hsTropT, high-sensitive troponin T-value.

Similar findings were reported in ACS patients treated with liraglutide (53-55). However, patients enrolled in these studies were not required to be hyperglycemic. Empagliflozin, a SGLT2 inhibitor, were reported to reduce LV mass and improve diastolic function in patients with ACS and diabetes (56). Nevertheless, further human studies are needed for evaluation of the cardiovascular outcome of both drugs in the presence of ACS with SIH.

So far, given limited results from clinical trials, there're no unified recommendations on the optimal glucose target and therapeutic strategy for SIH in the ACS setting. A scientific statement from AHA recommended initiation of 


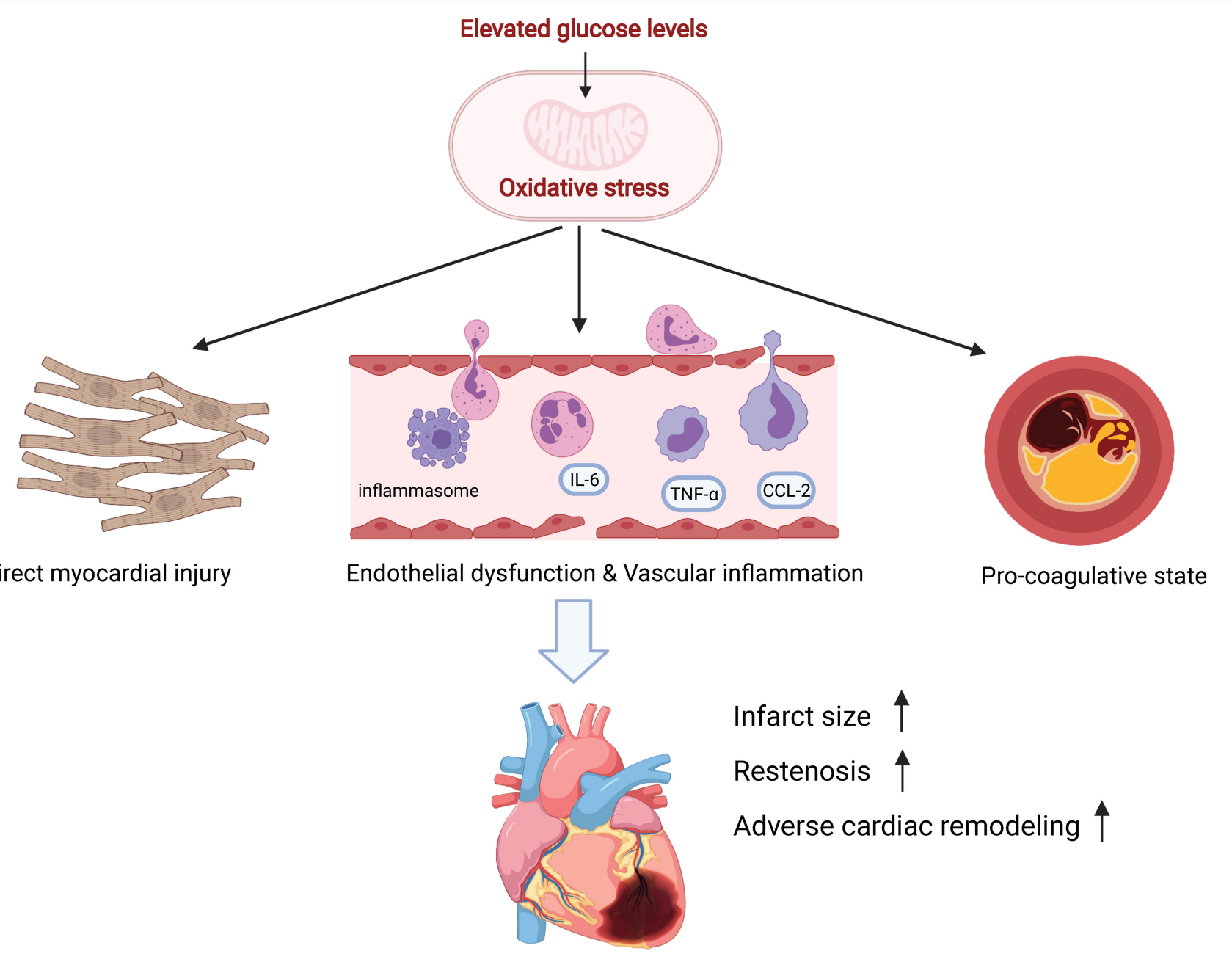

FIGURE 1 | Postulated mechanisms underlying detrimental effects of SIH.

intensive glucose control when plasma glucose was $>180$ $\mathrm{mg} / \mathrm{dL}$ (6). In contrast, NICE recommendations suggested to manage hyperglycemia in ACS patients by keeping blood glucose levels below $198 \mathrm{mg} / \mathrm{dL}$ (57). The most recent ESC guidelines on management of non-STEMI/STEMI recommended it's reasonable to keep the blood glucose concentration $<200$ $\mathrm{mg} / \mathrm{dL}(58,59)$. Anyway, absolute avoiding of hypoglycemia is consistent across various statements and guidelines. As most ACS patients are hospitalized in intensive care units, intravenous insulin infusion with close blood glucose monitoring is the recommended glucose-lowering strategy.

\section{MECHANISMS}

Depending on baseline glucose metabolic status, the mechanisms underlying SIH could be very different (60). The development of $\mathrm{SIH}$ in patients without established diabetes mellitus in the context of ACS probably results from a combination of pancreatic $\beta$-cell dysfunction and acute insulin resistance (60,
61). Beta cell responsiveness was significantly related to ABG amongst patients with AMI (62). Furthermore, plasma proinsulin concentration and the proinsulin/insulin ratio were higher in AMI patients compared to control populations (63). These results indicated $\beta$-cell dysfunction might be prevalent among patients suffering AMI. Besides, glucose production is enhanced by upregulation of both gluconeogenesis and glycogenolysis. A complicated interplay of neurohormones and cytokines plays an important role in the development of hyperglycemia during ACS (64). In particular, excessive glucagon is the primary mediator of augmented glucogenesis. Sympathetic nervous system activation stimulates glucagon release, together with other anti-insulin hormones including cortisol and growth hormone, leading to hyperglycemia $(65,66)$. Cytokines, for example, tumor necrosis factor- $\alpha(\mathrm{TNF} \alpha)$, could promote gluconeogenesis via stimulation of glucagon production (67). Meanwhile, acute insulin resistance develops through two major pathways, including impaired post-receptor insulin signaling and downregulation of glucose transporter-4 (68). Both cytokines, such as TNF $\alpha$ and interleukin 1 , and stimulation of $\beta$-adrenergic 
receptors can inhibit post-receptor insulin signaling (69-72). Overproduction of cortisol also reduces insulin-mediated glucose uptake (73). Additionally, insulin resistance promotes lipolysis because of a catabolic state. In turn, the resultant excessive circulating free fatty acids exacerbate insulin resistance by disrupting insulin signaling and glycogen synthase $(74,75)$.

It's accepted that oxidative stress plays an important role in myocardial reperfusion injury as well as post-infarction remodeling $(76,77)$. Meanwhile, insights from both animal and human studies highlighted the role of increased oxidative stress in the pathophysiology of SIH (78-81). In turn, increased oxidative stress resulted in various tissue damaging via certain intracellular pathways, including the inflammatory and the nonoxidative glucose pathways (NOGPs) (60). Taking together, exacerbated oxidative stress during $\mathrm{SIH}$ might be a plausible mechanism responsible for additive subsequent detrimental effects in the ACS setting (Figure 1). First, acute hyperglycemia exerts a direct harmful effect on ischemic myocardium, probably via interfering with remote ischemic preconditioning (RIPerC). Kersten et al. showed that acute hyperglycemia abolished RIPerC induced cardioprotection and increased myocardial infarct size in a dose-dependent way (82). Similar finding was reported by Baranyai et al. in a rat model (83). However, some evidence suggested that chronic hyperglycemia reduced the infarct size and improved systolic function in rats after MI (84). Mechanisms underlying the cardioprotective effect of chronic hyperglycemia could be reduced cell necrosis, proinflammatory cytokines, and increased cell survival factors expression (84, 85). It seems that chronic hyperglycemia ahead of MI sets up a cellular preconditioning in response to acute rise of blood glucose. Secondly, both exacerbated vascular inflammation and endothelial cell dysfunction were implicated in the context of SIH $(39,86)$. Several studies showed an association of higher glucose levels with increased markers of vascular inflammation, including C-reactive protein, interleukin- 6 and TNF- $\alpha(87,88)$. Besides, hyperglycemia was reported to increase activation of prothrombotic factors, such as fibrinopeptide A and factor VII, and decrease plasma fibrinolytic activity (89-91). In an analysis of coronary thrombus from patients with STEMI, hyperglycemic patients showed a higher thrombus size, erythrocyte, fibrin, and macrophage levels (92). Finally, increasing studies implicated an association of SIH with post-infarct left ventricular systolic dysfunction $(93,94)$. Nevertheless, the underlying mechanisms need further illustration.

\section{REFERENCES}

1. Capes SE, Hunt D, Malmberg K, Gerstein HC. Stress hyperglycaemia and increased risk of death after myocardial infarction in patients with and without diabetes: a systematic overview. Lancet. (2000) 355:773-8. doi: 10.1016/S0140-6736(99)08415-9

2. Oswald G, Corcoran S, Yudkin J. Prevalence and risks of hyperglycaemia and undiagnosed diabetes in patients with acute myocardial infarction. Lancet. (1984) 323:1264-7. doi: 10.1016/S0140-6736(84)92447-4

3. Datey KK, Nanda NC. Hyperglycemia after acute myocardial infarction. Its relation to diabetes mellitus. $N$ Engl J Med. (1967) 276:262-5. doi: 10.1056/NEJM196702022760504

\section{DISCUSSIONS}

In this brief review, we discussed the definition, effects on clinical outcome, management, and pathophysiology of $\mathrm{SIH}$ in the context of ACS. A precise definition of SIH is helpful for designing interventional trials about glucose control in ACS patients. Only in this way, can we have high quality trials that shed lights on the nature of SIH. Therefore, we mainly focused on how to precisely define SIH. An optimal glucose metrics defining SIH should fulfill the following criteria that it correlates well with both short- and long-term outcomes regardless of the prior diabetic status. Unfortunately, a single glucose metrics seems unable to fulfill such criteria with present methodology. In the future, a combination of glucose metrics used to define SIH is reasonable and needs further investigations. We have fully understood that $\mathrm{SIH}$ is independently associated with adverse outcome of patients with ACS. However, it remains to be illustrated whether it's a marker of disease severity or a risk factor contributing directly to the poor clinical outcome. To address the issue, both clinical trials utilizing a unified precise definition of SIH and basic experiments revealing the underlying mechanisms are in demand. We suggest that researchers consider to set different glucose targets for patients with or without recognized diabetes mellitus in the future clinical trials targeting $\mathrm{SIH}$ in patients with ACS. With regards to underlying mechanisms, difference between the pathophysiological response of patients with or without previous persistent hyperglycemia should be taken into consideration.

\section{AUTHOR CONTRIBUTIONS}

ML, GC, and YF wrote the manuscript. XH revised the manuscript. All authors contributed to the article and approved the submitted version.

\section{FUNDING}

This work was supported by the National Key Research and Development Program of China (No. 2016YFC1301305); the Natural Science Foundation of Guangdong Province, China (Grant No. 2017A030313476) and Guangdong Provincial Key Laboratory of Coronary Artery Disease Prevention Fund (Z02207016).

4. Kosiborod M, Rathore SS, Inzucchi SE, Masoudi FA, Wang Y, Havranek EP, et al. Admission glucose and mortality in elderly patients hospitalized with acute myocardial infarction: implications for patients with and without recognized diabetes. Circulation. (2005) 111:3078-86. doi: 10.1161/CIRCULATIONAHA.104.517839

5. Kadri Z, Danchin N, Vaur L, Cottin Y, Gueret P, Zeller M, et al. Major impact of admission glycaemia on 30 day and one year mortality in non-diabetic patients admitted for myocardial infarction: results from the nationwide French USIC 2000 study. Heart. (2006) 92:910-5. doi: 10.1136/hrt.2005.073791

6. Deedwania P, Kosiborod M, Barrett E, Ceriello A, Isley W, Mazzone T, et al. Hyperglycemia and acute coronary syndrome: a scientific statement 
from the American Heart Association Diabetes Committee of the Council on Nutrition, Physical Activity, and Metabolism. Circulation. (2008) 117:1610-9. doi: 10.1161/CIRCULATIONAHA.107.188629

7. Kosiborod M, Inzucchi SE, Krumholz HM, Xiao L, Jones PG, Fiske S, et al. Glucometrics in patients hospitalized with acute myocardial infarction: defining the optimal outcomes-based measure of risk. Circulation. (2008) 117:1018-27. doi: 10.1161/CIRCULATIONAHA.107.740498

8. Hao Y, Lu Q, Li T, Yang G, Hu P, Ma A. Admission hyperglycemia and adverse outcomes in diabetic and non-diabetic patients with non-ST-elevation myocardial infarction undergoing percutaneous coronary intervention. $B M C$ Cardiovasc Disord. (2017) 17:6. doi: 10.1186/s12872-016-0441-x

9. Liao WI, Lin CS, Lee CH, Wu YC, Chang WC, Hsu CW, et al. An elevated glycemic gap is associated with adverse outcomes in diabetic patients with acute myocardial infarction. Sci Rep. (2016) 6:27770. doi: 10.1038/srep27770

10. Kojima T, Hikoso S, Nakatani D, Suna S, Dohi T, Mizuno H, et al. Impact of hyperglycemia on long-term outcome in patients with STsegment elevation myocardial infarction. Am J Cardiol. (2020) 125:851-9. doi: 10.1016/j.amjcard.2019.12.034

11. Bellodi G, Manicardi V, Malavasi V, Veneri L, Bernini G, Bossini $\mathrm{P}$, et al. Hyperglycemia and prognosis of acute myocardial infarction in patients without diabetes mellitus. Am J Cardiol. (1989) 64:885-8. doi: 10.1016/0002-9149(89)90836-9

12. Foo K, Cooper J, Deaner A, Knight C, Suliman A, Ranjadayalan K, et al. A single serum glucose measurement predicts adverse outcomes across the whole range of acute coronary syndromes. Heart. (2003) 89:512-6. doi: 10.1136/heart.89.5.512

13. Ritsinger V, Jensen J, Ohm D, Omerovic E, Koul S, Frobert O, et al. Elevated admission glucose is common and associated with high shortterm complication burden after acute myocardial infarction: insights from the VALIDATE-SWEDEHEART study. Diab Vasc Dis Res. (2019) 16:582-4. doi: $10.1177 / 1479164119871540$

14. Goyal A, Mahaffey KW, Garg J, Nicolau JC, Hochman JS, Weaver WD, et al. Prognostic significance of the change in glucose level in the first $24 \mathrm{~h}$ after acute myocardial infarction: results from the CARDINAL study. Eur Heart J. (2006) 27:1289-97. doi: 10.1093/eurheartj/ehi884

15. Buturlin K, Minha S, Rozenbaum Z, Neuman Y, Shlezinger M, Goldenberg I, et al. Admission plasma glucose levels within the normal to mildly impaired range and the outcome of patients with acute coronary syndrome. Eur Heart J Acute Cardiovasc Care. (2017) 6:738-43. doi: 10.1177/2048872616641900

16. Roberts GW, Quinn SJ, Valentine N, Alhawassi T, O’Dea H, Stranks SN, et al. Relative hyperglycemia, a marker of critical illness: introducing the stress hyperglycemia ratio. J Clin Endocrinol Metab. (2015) 100:4490-7. doi: $10.1210 /$ jc. $2015-2660$

17. Marenzi G, Cosentino N, Milazzo V, De Metrio M, Cecere M, Mosca S, et al. Prognostic value of the acute-to-chronic glycemic ratio at admission in acute myocardial infarction: a prospective study. Diabetes Care. (2018) 41:847-53. doi: $10.2337 / \mathrm{dc} 17-1732$

18. Chen PC, Tsai SH, Wang JC, Tzeng YS, Wang YC, Chu CM, et al. An elevated glycemic gap predicts adverse outcomes in diabetic patients with necrotizing fasciitis. PLoS ONE. (2019) 14:e0223126. doi: 10.1371/journal.pone.02 23126

19. Gao S, Liu Q, Ding X, Chen H, Zhao X, Li H. Predictive value of the acute-to-chronic glycemic ratio for in-hospital outcomes in patients with ST-segment elevation myocardial infarction undergoing percutaneous coronary intervention. Angiology. (2020) 71:38-47. doi: 10.1177/00033197198 75632

20. Yang Y, Kim TH, Yoon KH, Chung WS, Ahn Y, Jeong MH, et al. The stress hyperglycemia ratio, an index of relative hyperglycemia, as a predictor of clinical outcomes after percutaneous coronary intervention. Int J Cardiol. (2017) 241:57-63. doi: 10.1016/j.ijcard.2017.02.065

21. Monnier L, Mas E, Ginet C, Michel F, Villon L, Cristol JP, et al. Activation of oxidative stress by acute glucose fluctuations compared with sustained chronic hyperglycemia in patients with type 2 diabetes. JAMA. (2006) 295:1681-7. doi: 10.1001/jama.295.14.1681

22. Ceriello A, Esposito K, Piconi L, Ihnat MA, Thorpe JE, Testa R, et al. Oscillating glucose is more deleterious to endothelial function and oxidative stress than mean glucose in normal and type 2 diabetic patients. Diabetes. (2008) 57:1349-54. doi: 10.2337/db08-0063
23. Krinsley JS. Glycemic variability: a strong independent predictor of mortality in critically ill patients. Crit Care Med. (2008) 36:3008-13. doi: 10.1097/CCM.0b013e31818b38d2

24. Su G, Mi SH, Tao H, Li Z, Yang HX, Zheng H, et al. Impact of admission glycemic variability, glucose, and glycosylated hemoglobin on major adverse cardiac events after acute myocardial infarction. Diabetes Care. (2013) 36:1026-32. doi: 10.2337/dc12-0925

25. Mi SH, Su G, Yang HX, Zhou Y, Tian L, Zhang T, et al. Comparison of in-hospital glycemic variability and admission blood glucose in predicting short-term outcomes in non-diabetes patients with ST elevation myocardial infarction underwent percutaneous coronary intervention. Diabetol Metab Syndr. (2017) 9:20. doi: 10.1186/s13098-017-0217-1

26. Takahashi H, Iwahashi N, Kirigaya J, Kataoka S, Minamimoto Y, Gohbara M, et al. Glycemic variability determined with a continuous glucose monitoring system can predict prognosis after acute coronary syndrome. Cardiovasc Diabetol. (2018) 17:116. doi: 10.1186/s12933-018-0761-5

27. Gerbaud E, Darier R, Montaudon M, Beauvieux MC, Coffin-Boutreux C, Coste $\mathrm{P}$, et al. Glycemic variability is a powerful independent predictive factor of midterm major adverse cardiac events in patients with diabetes with acute coronary syndrome. Diabetes Care. (2019) 42:674-81. doi: 10.2337/dc18-2047

28. Pu Z, Lai L, Yang X, Wang Y, Dong P, Wang D, et al. Acute glycemic variability on admission predicts the prognosis in hospitalized patients with coronary artery disease: a meta-analysis. Endocrine. (2020) 67:526-34. doi: 10.1007/s12020-019-02150-1

29. Siegelaar SE, Holleman F, Hoekstra JB, DeVries JH. Glucose variability; does it matter? Endocr Rev. (2010) 31:171-82. doi: 10.1210/er.2009-0021

30. Bergenstal RM. Glycemic variability and diabetes complications: does it matter? Simply put, there are better glycemic markers! Diabetes Care. (2015) 38:1615-21. doi: 10.2337/dc15-0099

31. Suleiman M, Hammerman H, Boulos M, Kapeliovich MR, Suleiman A, Agmon $\mathrm{Y}$, et al. Fasting glucose is an important independent risk factor for 30day mortality in patients with acute myocardial infarction: a prospective study. Circulation. (2005) 111:754-60. doi: 10.1161/01.CIR.0000155235.48601.2A

32. Aronson D, Hammerman H, Kapeliovich MR, Suleiman A, Agmon Y, Beyar $\mathrm{R}$, et al. Fasting glucose in acute myocardial infarction: incremental value for long-term mortality and relationship with left ventricular systolic function. Diabetes Care. (2007) 30:960-6. doi: 10.2337/dc06-1735

33. Ye $\mathrm{N}$, Yang $\mathrm{L}$, Wang $\mathrm{G}$, Bian $\mathrm{W}, \mathrm{Xu} \mathrm{F}, \mathrm{Ma} \mathrm{C}$, et al. Admission fasting plasma glucose is associated with in-hospital outcomes in patients with acute coronary syndrome and diabetes: findings from the improving care for cardiovascular disease in China-acute coronary syndrome (CCC-ACS) project. BMC Cardiovasc Disord. (2020) 20:380. doi: 10.1186/s12872-020-01662-3

34. Malmberg K, Rydén L, Efendic S, Herlitz J, Nicol P, Waldenstrom A, et al. Randomized trial of insulin-glucose infusion followed by subcutaneous insulin treatment in diabetic patients with acute myocardial infarction (DIGAMI study): effects on mortality at 1 year. J Am Coll Cardiol. (1995) 26:57-65. doi: 10.1016/0735-1097(95)00126-K

35. Malmberg K, Norhammar A, Wedel H, Ryden L. Glycometabolic state at admission: important risk marker of mortality in conventionally treated patients with diabetes mellitus and acute myocardial infarction: longterm results from the diabetes and insulin-glucose infusion in acute myocardial infarction (DIGAMI) study. Circulation. (1999) 99:2626-32. doi: 10.1161/01.CIR.99.20.2626

36. Malmberg K, Ryden L, Wedel H, Birkeland K, Bootsma A, Dickstein K, et al. Intense metabolic control by means of insulin in patients with diabetes mellitus and acute myocardial infarction (DIGAMI 2): effects on mortality and morbidity. Eur Heart J. (2005) 26:650-61. doi: 10.1093/eurheartj/ehi199

37. Cheung NW, Wong VW, McLean M. The hyperglycemia: intensive insulin infusion in infarction (HI-5) study: a randomized controlled trial of insulin infusion therapy for myocardial infarction. Diabetes Care. (2006) 29:765-70. doi: $10.2337 /$ diacare.29.04.06.dc05-1894

38. Nerenberg KA, Goyal A, Xavier D, Sigamani A, Ng J, Mehta SR, et al. Piloting a novel algorithm for glucose control in the coronary care unit: the RECREATE (researching coronary reduction by appropriately targeting euglycemia) trial. Diabetes Care. (2012) 35:19-24. doi: 10.2337/dc11-0706

39. Marfella R, Di Filippo C, Portoghese M, Ferraraccio F, Rizzo MR, Siniscalchi $\mathrm{M}$, et al. Tight glycemic control reduces heart inflammation and remodeling 
during acute myocardial infarction in hyperglycemic patients. J Am Coll Cardiol. (2009) 53:1425-36. doi: 10.1016/j.jacc.2009.01.041

40. Marfella R, Sasso FC, Siniscalchi M, Paolisso P, Rizzo MR, Ferraro F, et al. Peri-procedural tight glycemic control during early percutaneous coronary intervention is associated with a lower rate of in-stent restenosis in patients with acute ST-elevation myocardial infarction. J Clin Endocrinol Metab. (2012) 97:2862-71. doi: 10.1210/jc.2012-1364

41. Marfella R, Rizzo MR, Siniscalchi M, Paolisso P, Barbieri M, Sardu C, et al. Peri-procedural tight glycemic control during early percutaneous coronary intervention up-regulates endothelial progenitor cell level and differentiation during acute ST-elevation myocardial infarction: effects on myocardial salvage. Int J Cardiol. (2013) 168:3954-62. doi: 10.1016/j.ijcard.2013.06.053

42. de Mulder M, Umans VA, Cornel JH, van der Zant FM, Stam F, Oemrawsingh $\mathrm{RM}$, et al. Intensive glucose regulation in hyperglycemic acute coronary syndrome: results of the randomized BIOMarker study to identify the acute risk of a coronary syndrome-2 (BIOMArCS-2) glucose trial. JAMA Intern Med. (2013) 173:1896-904. doi: 10.1001/jamainternmed.2013.10074

43. van den Berg VJ, Umans VA, Stam F, de Mulder M, Akkerhuis KM, Cornel $\mathrm{JH}$, et al. Long-term follow-up of the randomized (BIOMArCS-2) glucose trial: intensive glucose regulation in hyperglycemic acute coronary syndrome. Circulation. (2016) 134:984-6. doi: 10.1161/CIRCULATIONAHA.116.023480

44. Wiviott SD, Raz I, Bonaca MP, Mosenzon O, Kato ET, Cahn A, et al. Dapagliflozin and cardiovascular outcomes in type 2 diabetes. $N$ Engl J Med. (2019) 380:347-57. doi: 10.1056/NEJMoa1812389

45. Zinman B, Wanner C, Lachin JM, Fitchett D, Bluhmki E, Hantel S, et al. Empagliflozin, cardiovascular outcomes, and mortality in type 2 diabetes. $N$ Engl J Med. (2015) 373:2117-28. doi: 10.1056/NEJMoa1504720

46. Bethel MA, Patel RA, Merrill P, Lokhnygina Y, Buse JB, Mentz RJ, et al. Cardiovascular outcomes with glucagon-like peptide-1 receptor agonists in patients with type 2 diabetes: a meta-analysis. Lancet Diabetes Endocrinol. (2018) 6:105-13. doi: 10.1016/S2213-8587(17)30412-6

47. Bose AK, Mocanu MM, Carr RD, Brand CL, Yellon DM. Glucagon-like peptide 1 can directly protect the heart against ischemia/reperfusion injury. Diabetes. (2005) 54:146-51. doi: 10.2337/diabetes.54.1.146

48. Sonne DP, Engstrom T, Treiman M. Protective effects of GLP-1 analogues exendin-4 and GLP-1(9-36) amide against ischemia-reperfusion injury in rat heart. Regul Pept. (2008) 146:243-9. doi: 10.1016/j.regpep.2007.10.001

49. Lahnwong S, Palee S, Apaijai N, Sriwichaiin S, Kerdphoo S, Jaiwongkam T, et al. Acute dapagliflozin administration exerts cardioprotective effects in rats with cardiac ischemia/reperfusion injury. Cardiovasc Diabetol. (2020) 19:91. doi: 10.1186/s12933-020-01066-9

50. Lee TM, Chang NC, Lin SZ. Dapagliflozin, a selective SGLT2 inhibitor, attenuated cardiac fibrosis by regulating the macrophage polarization via STAT3 signaling in infarcted rat hearts. Free Radic Biol Med. (2017) 104:298310. doi: 10.1016/j.freeradbiomed.2017.01.035

51. Tanajak P, Sa-Nguanmoo P, Sivasinprasasn S, Thummasorn S, Siri-Angkul N, Chattipakorn SC, et al. Cardioprotection of dapagliflozin and vildagliptin in rats with cardiac ischemia-reperfusion injury. J Endocrinol. (2018) 236:69-84. doi: 10.1530/JOE-17-0457

52. Lonborg J, Vejlstrup N, Kelbaek H, Botker HE, Kim WY, Mathiasen $\mathrm{AB}$, et al. Exenatide reduces reperfusion injury in patients with STsegment elevation myocardial infarction. Eur Heart J. (2012) 33:1491-9. doi: 10.1093/eurheartj/ehr309

53. Chen WR, Chen YD, Tian F, Yang N, Cheng LQ, Hu SY, et al. Effects of liraglutide on reperfusion injury in patients with ST-segmentelevation myocardial infarction. Circ Cardiovasc Imaging. (2016) 9:146. doi: 10.1161/CIRCIMAGING.116.005146

54. Chen WR, Hu SY, Chen YD, Zhang Y, Qian G, Wang J, et al. Effects of liraglutide on left ventricular function in patients with ST-segment elevation myocardial infarction undergoing primary percutaneous coronary intervention. Am Heart J. (2015) 170:845-54. doi: 10.1016/j.ahj.2015.07.014

55. Chen WR, Shen XQ, Zhang Y, Chen YD, Hu SY, Qian G, et al. Effects of liraglutide on left ventricular function in patients with nonST-segment elevation myocardial infarction. Endocrine. (2016) 52:516-26. doi: 10.1007/s12020-015-0798-0

56. Lan NSR, Yeap BB, Fegan PG, Green G, Rankin JM, Dwivedi G. Empagliflozin and left ventricular diastolic function following an acute coronary syndrome in patients with type 2 diabetes. Int J Cardiovasc Imaging. (2021) 37:517-27. doi: 10.1007/s10554-020-02034-w

57. Corbett SJ. NICE recommendations for the management of hyperglycaemia in acute coronary syndrome. Heart. (2012) 98:1189-91. doi: 10.1136/heartjnl-2012-302421

58. Collet JP, Thiele H, Barbato E, Barthelemy O, Bauersachs J, Bhatt DL, et al. 2020 ESC Guidelines for the management of acute coronary syndromes in patients presenting without persistent ST-segment elevation. Eur Heart J. (2021) 42:1289-367. doi: 10.1093/eurheartj/ehaa575

59. Ibanez B, James S, Agewall S, Antunes MJ, Bucciarelli-Ducci C, Bueno H, et al. 2017 ESC guidelines for the management of acute myocardial infarction in patients presenting with ST-segment elevation: the task force for the management of acute myocardial infarction in patients presenting with STsegment elevation of the European Society of Cardiology (ESC). Eur Heart J. (2018) 39:119-77. doi: 10.1093/eurheartj/ehx393

60. Dungan KM, Braithwaite SS, Preiser J-C. Stress hyperglycaemia. Lancet. (2009) 373:1798-807. doi: 10.1016/S0140-6736(09)60553-5

61. Bellis A, Mauro C, Barbato E, Ceriello A, Cittadini A, Morisco C. Stress-induced hyperglycaemia in non-diabetic patients with acute coronary syndrome: from molecular mechanisms to new therapeutic perspectives. Int $J$ Mol Sci. (2021) 22:775. doi: 10.3390/ijms22020775

62. Wallander M, Bartnik M, Efendic S, Hamsten A, Malmberg K, Ohrvik J, et al. Beta cell dysfunction in patients with acute myocardial infarction but without previously known type 2 diabetes: a report from the GAMI study. Diabetologia. (2005) 48:2229-35. doi: 10.1007/s00125-005-1931-z

63. Bartnik M, Malmberg K, Hamsten A, Efendic S, Norhammar A, Silveira A, et al. Abnormal glucose tolerance-a common risk factor in patients with acute myocardial infarction in comparison with population-based controls. J Intern Med. (2004) 256:288-97. doi: 10.1111/j.1365-2796.2004.01371.x

64. Vanhorebeek I, Van den Berghe G. Diabetes of injury: novel insights. Endocrinol Metab Clin North Am. (2006) 35:859-72, x. doi: $10.1016 /$ j.ecl.2006.09.002

65. Shamoon H, Hendler R, Sherwin RS. Synergistic interactions among antiinsulin hormones in the pathogenesis of stress hyperglycemia in humans. J Clin Endocrinol Metab. (1981) 52:1235-41. doi: 10.1210/jcem-52-6-1235

66. Dunser MW, Hasibeder WR. Sympathetic overstimulation during critical illness: adverse effects of adrenergic stress. J Intensive Care Med. (2009) 24:293-316. doi: 10.1177/0885066609340519

67. Blumberg D, Hochwald S, Burt M, Donner D, Brennan MF. Tumor necrosis factor alpha stimulates gluconeogenesis from alanine in vivo. J Surg Oncol. (1995) 59:220-4; discussion 4-5. doi: 10.1002/jso.2930590404

68. Lang $\mathrm{CH}$, Dobrescu C, Meszaros K. Insulin-mediated glucose uptake by individual tissues during sepsis. Metabolism. (1990) 39:1096-107. doi: 10.1016/0026-0495(90)90172-9

69. Ishizuka K, Usui I, Kanatani Y, Bukhari A, He J, Fujisaka S, et al. Chronic tumor necrosis factor-alpha treatment causes insulin resistance via insulin receptor substrate-1 serine phosphorylation and suppressor of cytokine signaling-3 induction in 3T3-L1 adipocytes. Endocrinology. (2007) 148:29943003. doi: 10.1210/en.2006-1702

70. He J, Usui I, Ishizuka K, Kanatani Y, Hiratani K, Iwata M, et al. Interleukin1alpha inhibits insulin signaling with phosphorylating insulin receptor substrate-1 on serine residues in 3T3-L1 adipocytes. Mol Endocrinol. (2006) 20:114-24. doi: 10.1210/me.2005-0107

71. Klein J, Fasshauer M, Ito M, Lowell BB, Benito M, Kahn CR. beta(3)adrenergic stimulation differentially inhibits insulin signaling and decreases insulin-induced glucose uptake in brown adipocytes. J Biol Chem. (1999) 274:34795-802. doi: 10.1074/jbc.274.49.34795

72. Deibert DC, DeFronzo RA. Epinephrine-induced insulin resistance in man. $J$ Clin Invest. (1980) 65:717-21. doi: 10.1172/JCI109718

73. Dimitriadis G, Leighton B, Parry-Billings M, Sasson S, Young M, Krause U, et al. Effects of glucocorticoid excess on the sensitivity of glucose transport and metabolism to insulin in rat skeletal muscle. Biochem J. (1997) 321:707-12. doi: 10.1042/bj3210707

74. Dresner A, Laurent D, Marcucci M, Griffin ME, Dufour S, Cline GW, et al. Effects of free fatty acids on glucose transport and IRS-1-associated phosphatidylinositol 3-kinase activity. J Clin Invest. (1999) 103:253-9. doi: 10.1172/JCI5001 
75. Kelley DE, Mokan M, Simoneau JA, Mandarino LJ. Interaction between glucose and free fatty acid metabolism in human skeletal muscle. J Clin Invest. (1993) 92:91-8. doi: 10.1172/JCI116603

76. Kloner RA, Przyklenk K, Whittaker P. Deleterious effects of oxygen radicals in ischemia/reperfusion. Resolved and unresolved issues. Circulation. (1989) 80:1115-27. doi: 10.1161/01.CIR.80.5.1115

77. Nian $M$, Lee $P$, Khaper $N$, Liu $P$. Inflammatory cytokines and postmyocardial infarction remodeling. Circ Res. (2004) 94:1543-53. doi: 10.1161/01.RES.0000130526.20854.fa

78. Su H, Ji L, Xing W, Zhang W, Zhou H, Qian X, et al. Acute hyperglycaemia enhances oxidative stress and aggravates myocardial ischaemia/reperfusion injury: role of thioredoxin-interacting protein. J Cell Mol Med. (2013) 17:18191. doi: 10.1111/j.1582-4934.2012.01661.x

79. Mohanty P, Hamouda W, Garg R, Aljada A, Ghanim H, Dandona P. Glucose challenge stimulates reactive oxygen species (ROS) generation by leucocytes. J Clin Endocrinol Metab. (2000) 85:2970-3. doi: 10.1210/jcem.85.8.6854

80. Esposito K, Nappo F, Marfella R, Giugliano G, Giugliano F, Ciotola $\mathrm{M}$, et al. Inflammatory cytokine concentrations are acutely increased by hyperglycemia in humans: role of oxidative stress. Circulation. (2002) 106:2067-72. doi: 10.1161/01.CIR.0000034509.14906.AE

81. Mapanga RF, Joseph D, Symington B, Garson KL, Kimar C, Kelly-Laubscher $\mathrm{R}$, et al. Detrimental effects of acute hyperglycaemia on the rat heart. Acta Physiol (Oxf). (2014) 210:546-64. doi: 10.1111/apha.12184

82. Kersten JR, Schmeling TJ, Orth KG, Pagel PS, Warltier DC. Acute hyperglycemia abolishes ischemic preconditioning in vivo. Am J Physiol. (1998) 275:H721-5. doi: 10.1152/ajpheart.1998.275.2.H721

83. Baranyai T, Nagy CT, Koncsos G, Onodi Z, Karolyi-Szabo M, Makkos A, et al. Acute hyperglycemia abolishes cardioprotection by remote ischemic perconditioning. Cardiovasc Diabetol. (2015) 14:151. doi: 10.1186/s12933-015-0313-1

84. Malfitano C, Alba Loureiro TC, Rodrigues B, Sirvente R, Salemi VM, Rabechi $\mathrm{NB}$, et al. Hyperglycaemia protects the heart after myocardial infarction: aspects of programmed cell survival and cell death. Eur J Heart Fail. (2010) 12:659-67. doi: 10.1093/eurjhf/hfq053

85. Schaffer SW, Croft CB, Solodushko V. Cardioprotective effect of chronic hyperglycemia: effect on hypoxia-induced apoptosis and necrosis. Am J Physiol Heart Circ Physiol. (2000) 278:H1948-54. doi: 10.1152/ajpheart.2000.278.6.H1948

86. Qiu C, Sui J, Zhang Q, Wei P, Wang P, Fu Q. Relationship of endothelial cell-specific molecule 1 level in stress hyperglycemia patients with acute STsegment elevation myocardial infarction: a pilot study. Angiology. (2016) 67:829-34. doi: 10.1177/0003319715621996
87. Morohoshi M, Fujisawa K, Uchimura I, Numano F. The effect of glucose and advanced glycosylation end products on IL-6 production by human monocytes. Ann N Y Acad Sci. (1995) 748:562-70. doi: 10.1111/j.1749-6632.1994.tb17362.x

88. Morohoshi M, Fujisawa K, Uchimura I, Numano F. Glucosedependent interleukin 6 and tumor necrosis factor production by human peripheral blood monocytes in vitro. Diabetes. (1996) 45:954-9. doi: 10.2337/diabetes.45.7.954

89. Pandolfi A, Giaccari A, Cilli C, Alberta MM, Morviducci L, De Filippis EA, et al. Acute hyperglycemia and acute hyperinsulinemia decrease plasma fibrinolytic activity and increase plasminogen activator inhibitor type 1 in the rat. Acta Diabetol. (2001) 38:71-6. doi: 10.1007/s005920170016

90. Ceriello A, Giugliano D, Quatraro A, Russo PD, Marchi E, Torella R. Hyperglycemia may determine fibrinopeptide a plasma level increase in humans. Metabolism. (1989) 38:1162-3. doi: 10.1016/0026-0495(89) 90152-2

91. Ceriello A, Giugliano D, Quatraro A, Dello Russo P, Torella R. Blood glucose may condition factor VII levels in diabetic and normal subjects. Diabetologia. (1988) 31:889-91. doi: 10.1007/BF00265372

92. D’Onofrio N, Sardu C, Paolisso P, Minicucci F, Gragnano F, Ferraraccio F, et al. MicroRNA-33 and SIRT1 influence the coronary thrombus burden in hyperglycemic STEMI patients. J Cell Physiol. (2020) 235:1438-52. doi: $10.1002 /$ jcp. 29064

93. Bauters C, Ennezat PV, Tricot O, Lauwerier B, Lallemant R, Saadouni H, et al. Stress hyperglycaemia is an independent predictor of left ventricular remodelling after first anterior myocardial infarction in non-diabetic patients. Eur Heart J. (2007) 28:546-52. doi: 10.1093/eurheartj/ehl546

94. Zhu Y, Liu K, Meng S, Jia R, Lei X, Chen M, et al. Augmented glycaemic gap is a marker for an increased risk of post-infarct left ventricular systolic dysfunction. Cardiovasc Diabetol. (2020) 19:101. doi: 10.1186/s12933-020-01075-8

Conflict of Interest: The authors declare that the research was conducted in the absence of any commercial or financial relationships that could be construed as a potential conflict of interest.

Copyright (C) $2021 \mathrm{Li}$, Chen, Feng and He. This is an open-access article distributed under the terms of the Creative Commons Attribution License (CC BY). The use, distribution or reproduction in other forums is permitted, provided the original author(s) and the copyright owner(s) are credited and that the original publication in this journal is cited, in accordance with accepted academic practice. No use, distribution or reproduction is permitted which does not comply with these terms. 